\title{
Antioxidant Activity of Green Tea Extract on Canola Oil Oxidation Stability: Comparison of Free and Liposomal extract
}

\author{
Shima Jahanfar ${ }^{1}$, Mehrdad Ghavami², Kianoush Khosravi-darani ${ }^{2}$, and Mahshid Jahadi ${ }^{3}$ \\ ${ }^{1}$ Islamic Azad University Science and Research Branch \\ ${ }^{2}$ Affiliation not available \\ ${ }^{3}$ Islamic Azad University Khorasgan Branch
}

May 20, 2020

\begin{abstract}
In the present study, green tea extract was encapsulated in liposomes prepared by Mozafari method (without any organic solvents) and characterized for its physicochemical properties e.g. encapsulation efficiency, particle size and z- potential. The obtained results for encapsulation efficiency, particles size and z- potential were 51.34, $419 \mathrm{~nm}$ and $-57 \mathrm{mV}$, respectively. Total polyphenol content of green tea was obtained $164.2 \mathrm{mg}$ gallic acid /g extract. Free radical scavenging activities of free and liposomal extract, with using DPPH method were measured $90.6 \%$ and $93.37 \%$ respectively. Antioxidant activity of ethanolic extract of green tea in free and liposomal form were measured at concentration of 200,600 and $1000 \mathrm{mg} / \mathrm{L}$ on the oxidative stability of canola oil during $60^{\circ} \mathrm{C}$ temperature for $0,4,8,12,16,20,24,28$ and 32 days. The results compared with synthetic antioxidant butylated hydroxytoluene at $200 \mathrm{mg} / \mathrm{L}$. To evaluate antioxidant activity on canola oil stability, peroxide value, Thiobarbitoric acid, anisidine value, TOTOX and rancimat test measured. Results showed that liposomal green tea extract acted more effective than free extracts. Also, $600 \mathrm{mg} / \mathrm{L}$ concentration of green tea extract showed significant antioxidant activity in compare to others. The increasing storage time and different concentrations of ethanolic green tea extracts had significant effects on canola oil stability (P[?]0.05). The obtained results showed green tea extract could act as an effective antioxidant. Green tea extract in free and liposomal form at $600 \mathrm{mg} / \mathrm{L}$ concentration resulted stronger function than butylated hydroxytoluene synthetic antioxidant.
\end{abstract}

\section{Antioxidant Activity of Green Tea Extract on Canola Oil Oxidation Stability: Comparison of Free and Liposomal extract}

\section{Shima Jahanfar ${ }^{a}$, Mehrdad Gahavami ${ }^{a}$, Kianoush Khosravi-Darani ${ }^{*}$, Mahshid Jahadic}

a Department of Food Science and Technology, Faculty of Agriculture and Natural Resources, Science and Research Branch, Islamic Azad University, Tehran, Iran.

b Department of Food Technology Research, National Nutrition and Food Technology Research Institute, Faculty of Nutrition Sciences and Food Technology, Shahid Beheshti University of Medical Sciences, P.O. Box: 19395-4741, Tehran, Iran.

${ }^{c}$ Department of Food Science and Technology, Isfahan (Khorasgan) Branch, Islamic Azad University, Isfahan, Iran.

Abstract: In the present study, green tea extract was encapsulated in liposomes prepared by Mozafari method (without any organic solvents) and characterized for its physicochemical properties e.g. encapsulation efficiency, particle size and z- potential. The obtained results for encapsulation efficiency, particles size and zpotential were $51.34,419 \mathrm{~nm}$ and $-57 \mathrm{mV}$, respectively. Total polyphenol content of green tea was obtained $164.2 \mathrm{mg}$ gallic acid /g extract. Free radical scavenging activities of free and liposomal extract, with using 
DPPH method were measured $90.6 \%$ and $93.37 \%$ respectively. Antioxidant activity of ethanolic extract of green tea in free and liposomal form were measured at concentration of 200,600 and $1000 \mathrm{mg} / \mathrm{L}$ on the oxidative stability of canola oil during $60^{\circ} \mathrm{C}$ temperature for $0,4,8,12,16,20,24,28$ and 32 days. The results compared with synthetic antioxidant butylated hydroxytoluene at $200 \mathrm{mg} / \mathrm{L}$. To evaluate antioxidant activity on canola oil stability, peroxide value, Thiobarbitoric acid, anisidine value, TOTOX and rancimat test measured. Results showed that liposomal green tea extract acted more effective than free extracts. Also, $600 \mathrm{mg} / \mathrm{L}$ concentration of green tea extract showed significant antioxidant activity in compare to others. The increasing storage time and different concentrations of ethanolic green tea extracts had significant effects on canola oil stability (P[?]0.05). The obtained results showed green tea extract could act as an effective antioxidant. Green tea extract in free and liposomal form at $600 \mathrm{mg} / \mathrm{L}$ concentration resulted stronger function than butylated hydroxytoluene synthetic antioxidant.

Keywords Green tea extract, Liposome, Canola oil, Oxidative stability

\section{Antioxidant Activity of Green Tea Extract on Canola Oil Oxidation Stability: Comparison of Free and Liposomal extract}

\section{Introduction}

One of the most consumption and nutritious edible oils in the world is canola oil. The unsaturated acids content in canola oil is higher than other vegetable oils. The ratio of linolenic acid $(\mathrm{C} 18: 3, \omega 3)$ to linoleic acid (C 18:3, $\omega 6)$ in this oil is about 1:2 that is desirable from the point of view nutrition (Shahidi., 1990). The high contents of unsaturated fatty acids in canola oil especially linolenic acid effect on its stability and quality (Tokarska et al., 1986). Lipids are more potential to autoxidation than other chemical components of an organic material. Triglycerides oxidation process rate depends on saturation degree and double bonds position in molecule (Yanishlieva-Maslarowa., 2001). One of the most effective ways to prevent oxidation and development off-flavour is addition antioxidants in foods containing fat (Jeong et al., 2004). Antioxidants as food additive are used to develop oils shelf life and fat-based foods during storage and processing (Bitar et al., 2008). The most extensive synthetic antioxidants useable are including tert-butyl hydroxy quinoline (TBHQ), butylated hydroxytoluene (BHT), butylated hydroxyanisole (BHA). However, there are too much worry about consumption safety these antioxidants such as carcinogenic effects (Jeong et al., 2004). The demand for using of natural antioxidants instead of synthetic ones have been increased increasing which cause to prevent of diseases and having healthy effects (Zhou \& Ly., 2004). Green tea has known as a potent natural antioxidant. This property strongly is related with the total phenolic content of green tea (Langley-Evans, 2000). Green tea leaves are a superior source of polyphenolic compounds that has shown anticancer properties versus several types of cancer (Ahmed et el., 2014), such as lung, skin, esophagus, liver, and stomach (Mandel et al., 2004). A main group of green tea polyphenols are catechins. Many researches have shown, tea catechins are included numerous therapeutic effects such as neuroprotective activity, prevent atherosclerosis, inhibit tumor angiogenesis and modulate cholesterol metabolism (Tang et al., 2013). The most importance catechins of green tea are including: epicatechin (EC), epicatechin-3-gallate (ECG), epigallocatechin (EGC), and epigallocatechin-3-gallate (EGCG) (Rains et al., 2011). Chander et al. reported green tea leaves (Camellia sinensis $L$.) contain polyphenolic components which have been known as strong antioxidants. One of the most polyphenolic components are catechins. Catechins reduce fatty acids oxidation ability by chelating iron and copper which cause to form catalyzed free radicals by metal (Chander et al., 2005). Ou et al. reported natural antioxidants compounds of green tea such as caffeic acid, cherogenic acid, quercetin, rutin and catechins have been acted as stronger antioxidants than vitamins C and E (Ou et al., 2001). Koketsu and Satoh. studied the antioxidant effect of green tea extract on the lard and soy bean oil. The green tea extract used in 20 and $40 \mathrm{mg} / \mathrm{L}$ levels. They stated, green tea polyphenols had stronger antioxidant properties compared with tocopherol in both lard and soy bean oil (Koketsu and Satoh., 1997). Despite the promising therapeutic effects of polyphenolic compounds under in vitro conditions and be contain strong antioxidant activity, their usage is limited due to various reasons including poor absorption and bioavailability (Zhang et al., 2004). In addition to, the tea polyphenols are unstable when exposed to light, heat and oxidants (Shpigelman et al., 2012). An effective method to 
overcome this problem is entrapment systems such as liposome, nanoparticle and microcapsule (Dsai \& Park., 2005). Liposomes possess a spherical structure along with an aqueous core that have surrounded by single or several lipid bilayers. The most important advantage of liposome structures is their ability to encapsulate both hydrophilic and lipophilic bioactive compounds (Liveny., 2015). Noudoost et al. prepared liposomes containing green tea polyphenols with thin film layer method which applied sonication process to reduce of particle size. They reported green tea polyphenols incorporated in liposome had significantly more antioxidant activity than free extract (Noudoost et al. (2015). Rasti et al. studied the oxidative and physical stability of liposomes and nanoliposomes containing docosahexaenoic and eicosapentaenoic acid, prepared by the thin film hydration technique and Mozafari method. They found prepared liposomes by Mozafari method had the most physicochemical stability (Rasti et al., 2012). Lu et al. prepared green tea extract liposome by the thin film ultrasonic dispersion method to increase the bioavailability of tea polyphenol. They reported that liposomes containing green tea polyphenol were stable and suitable for more widespread application ( $\mathrm{Lu}$ et al., 2011). Considering that harmful effects synthetic antioxidant, the purpose of this study was the evaluation green tea extract as a natural antioxidant on the oxidative stability of canola oil in two forms free and incorporated in liposome during storage at an oven at $60^{\circ} \mathrm{C}$ temperature and compare it with BHT as a synthetic antioxidant. For this purpose, green tea extract liposomes prepared with using Mozafari method without using any solvents.

\section{Materials and Methods}

\section{Materials}

Green tea plant (Camellia sinensis) belongs to the family Theaceae was obtained from Isfahan province (Iran), lecithin (99\%, granular phosphatidylcholine) was procured from Across Company (USA). Ethanol, glycerol, 2-2-diphenyl-1-pycrylhydrazyl (DPPH) and Folin-ciocalteu reagent were prepared from Merck Company, Germany, Particle size and Zeta-Sizer analyzer (Horiba scientific Instruments, SZ-100 Series Germany), ultracentrifuge (Herolab, Hicen, Germany), spectrophotometer model UV-6600 (Spectro Flex, Germany).

\section{Preparation of green tea extract}

Fresh green tea leaves were collected from tea gardens of Mazandaran province. Then, were sorted, washed, and were dried under sunlight. The dried tea leaves were crushed in a blender and then sieved using 70/100 mesh sieve-set (Setyopratomo., 2014). The extraction carried out by mixing $1000 \mathrm{ml}$ of $70 \%$ ethanol in distilled water to $100 \mathrm{~g}$ of green tea powder. The obtained mixture had agitated with a magnetic for 24 hours at $40{ }^{\circ} \mathrm{C}$ temperature. In the next stage, the extract separated by filtration. Then to obtain to a concentrate extract, the resultant liquid evaporated by oven at temperature $40{ }^{\circ} \mathrm{C}$. Finally, the extract was converted to powder by employing a freeze dryer at $-50^{\circ} \mathrm{C}$ and was kept in air-tight dark bottles in the freezer at $-18^{\circ} \mathrm{C}$ until usage (Vuong et al., 2011). Nwuha et al. reported the green tea polyphenols solubility in ethanol solvent was five to seven times higher than in the water extracts (Nwuha et al., 1999).

\section{Liposome preparation}

To prepare liposomes containing green tea extract, in this study, was applied of mozafari method. The superiority this method than other methods is the production of liposomes without using any solvent and detergent (Mozafari \& Khosravi-Darani., 2007). In addition to, in this method do not use of homogenization or sonication methods for reduction of particle size which cause to destruction of liposome structure. The green tea extract (0.7-2 \%) was first mixed with distilled water. Then phosphatidylcholine (2.5-4.5\%) and glycerol $(3 \% \mathrm{v} / \mathrm{v})$ were added to the green tea extract solution. The mixture was agitated on a hot plate stirrer at temperatures of $\left(50^{\circ}-70^{\circ} \mathrm{C}\right)$ for different time intervals $(30-60 \mathrm{~min})$ at a mixing speed of 1,000 $\mathrm{rpm}$. Finally, the mixture was placed at room temperature for one hour in order to increase the stability of the liposomes. The formulation was kept in a dark bottle at $4^{\circ} \mathrm{C}$ under nitrogen. Then, physicochemical properties of green tea liposomes measured such as encapsulation efficiency (EE), particle size and z- potential and determined optimal conditions to produce to green tea extract liposomes. In addition to, total polyphenol content of green tea and free radical scavenging activities of free and liposomal extract, with using DPPH method measured (Jahanfar et al., 2020). 


\section{Sample Preparation}

Green tea extracts in three concentration 200, 600 and $1000 \mathrm{mg} / \mathrm{L}$ and BHA in $200 \mathrm{mg} / \mathrm{L}$ level added to canola oil without antioxidant and then were placed in oven at $60^{\circ} \mathrm{C}$ temperature and oil samples were evaluated to determine oxidation processes progress. Control samples without any antioxidant were also placed under the same storage conditions.

\section{Oven Test}

Oil samples $(250 \mathrm{~g})$ were placed separately in glass dark bottles $300 \mathrm{ml}$ in oven at $60^{\circ} \mathrm{C}$ and then samples oxidative stability were evaluated at intervals $0,4,8,12,16,20,24,28$ and 32 days. The temperature of $60^{\circ} \mathrm{C}$ used as a rapid method to simulate the storage in real conditions (Besbes et al., 2004).

\section{Rancimat Test}

Rancimat test carried out according to Laubli \& Bruttel by the little modifications. During the lipid oxidation process are formed volatile acids that the rancimat test is based on the conductometric measurement of volatile acids. Oil samples $(2.5 \mathrm{~g})$ was oxidized in a reaction vessel at $140^{\circ} \mathrm{C}$ and air flow $(20 \mathrm{~L} / \mathrm{h})$. The end of the induction period (IP) was determined by the sudden increase of water conductivity, due to the dissociation of volatile carboxylic acids (Laubli \& Bruttel., 1986).

\section{Peroxide Value}

To determine peroxide value used of A.O.A.C (1984) method. From each of the oil samples, $2 \mathrm{~g}$ were weighed into different conical flasks. Then, $15 \mathrm{ml}$ of the mixture of $\mathrm{CH}_{3} \mathrm{COOH}$ and $\mathrm{CHCl}_{3}$ in the ratio of $3: 2$ was added to the oil samples respectively. In the next step, $0.5 \mathrm{ml}$ of saturated potassium iodide was added to each conical flask and allowed to stand for 5 minutes left in room temperature for 5 minutes, thereafter, $15 \mathrm{ml}$ of distilled water was added and titrated with $0.1 \mathrm{~N} \mathrm{Na} 2 \mathrm{~S} 2 \mathrm{O} 3$ until it appeared yellowish color. Finally, 0.5 $\mathrm{ml}$ of starch indicator was added and the titration continued to a colorless end-point. The peroxide value was calculated from the equation:

$$
\mathrm{PV}=\frac{(V 2-V 1) \times \mathrm{T}}{M} \times 1000
$$

where $\mathrm{M}=$ mass of oil taken $(2 \mathrm{~g}), \mathrm{V} 2=$ volume of Na2S2O3, $\mathrm{V} 1=$ volume of blank and $\mathrm{T}=$ normality of Na2S2 O3.

\section{Anisidine Value}

The measurement of anisidine value carried out according to AOCS Official method Cd, 18-90 (1996). For this purpose, $1 \mathrm{~g}$ oil sample mixed with iso-Octane into $25 \mathrm{ml}$ conical flasks. Then, $5 \mathrm{ml}$ of this solution mixed to $1 \mathrm{ml}$ of $0.25 \% \mathrm{p}$ - anisidine solution in glacial acetic acid. After 10 minutes, solution adsorption read in $350 \mathrm{~nm}$ wavelength by spectrophotometer model UV-6600 (spectroFlex, Germany). The anisidine value was calculated from the following equation:

$$
p-\text { Anisidine Value }=\frac{25 \times(1.2 A s-A b)}{m}
$$

$\mathrm{As}, \mathrm{Ab}$ and $\mathrm{m}$ is illustrative of solution adsorption before and after reaction with p-Anisidine solution, respectively.

\section{TOTOX Value}

TOTOX value is illustrative the total oxidation amount. This indicator measures first and secondary oxidation products. This index is expressed as TOTOX $=2 \mathrm{PV}+$ p-AV (Abbas Ali et al., 2013).

Thiobarbituric Acid (T.B.A) 
The TBA value was measured according to AOCS Official method Cd ,19-90 (1998). The TBA value calculated as mg malonaldehyde / kg sample.

\section{Statistical Analysis}

Statistical analysis was performed in triplicate. Results were expressed as the means and standard deviation. Significant differences between means of same sample were determined by Duncan's multiple range test using SPSS 26 software package. Differences were considered statistically significant at P[?]0.05.

\section{Results and Discussion}

\section{The Physicochemical Properties of Liposome}

The obtained amounts for EE, particles size and z- potential was $51.34,419 \mathrm{~nm}$ and $-57 \mathrm{mV}$, respectively (without any data). It should be noted, in this research, did not use of any method for particle size reduction (e.g. sonication, homogenization or extrusion). This matter caused to reduce executive stages, as well as to be economic. Also, these methods because of using of high stress and pressure, can destroy the membrane of liposome. The required energy to produce small liposomal particles supplied by magnet stirrer with agitation speed $1000 \mathrm{rpm}$ along with thermal treatment. Also, to prepare liposomes by Mozafari method, did not use any organic solvents or detergent. Because these solvents can cause production toxicity. In addition to, solvent remove processes are time-consuming and costly (Jahanfar et al., 2020)

\section{Rancimat Test}

The results of rancimat is visible in Figure 1. The lowest and highest stability belonged to control and green tea extract liposome in $1000 \mathrm{mg} / \mathrm{L}$ level. Oil samples containing green tea extract liposome had higher oxidative stability than free green tea. Green tea extract, in $1000 \mathrm{mg} / \mathrm{L}$ concentration, in the rancimat test, had the best oxidative stability, with induction period $9.5 \mathrm{~h}$, while in oven test showed the lower stability. The reason was that in the oven and rancimat test are used of 60 [?]C and $120^{\circ} \mathrm{C}$, respectively. In the high temperatures such as rancimat test, lipids oxidation mechanism significantly changes while in oven test, side reactions including polymerization and cyclization were in its minimum amount. The rate of oxidation depends to oxygen concentration and oxygen solubility, in the high temperatures, decreases (Frankel., 1993). Yin et al. studied the effect of green tea extract green tea (catechin at $0.25,0.5$ and 1 $\mu \mathrm{mol} / \mathrm{g}$ oil on the sunflower oil stability by rancimat test. Oil samples induction period had upward trend by increasing antioxidant concentration. Induction period for control and oils containing green tea extract in $0.25,0.5$ and $1 \mu \mathrm{mol} / \mathrm{g}$ oil concentrations was about 1.9, 4.8, 7.5 and 11.8, respectively (Yin et al., 2012). Gramza et al. evaluated the effect of antioxidant properties aqueous and ethanol green tea extracts at 200, 500 and $1000 \mathrm{mg} / \mathrm{L}$ on the sunflower stability in the rancimat test. They stated oil samples containing green tea ethanolic extracts at $1000 \mathrm{mg} / \mathrm{L}$ during $6.45 \mathrm{~h}$ induction period had the longest oxidative stability (Gramza et al., 2006).

\section{Fig. 1}

\section{Peroxide value}

One of the most common tests to evaluate progress rate of lipids oxidation is peroxide value. This test measures primary products of oxidation. The antioxidant effects green tea extracts as free and encapsulated in liposome on canola oil during oven test $60^{\circ} \mathrm{C}$ for 32 days have been shown in Table 1 . The green tea extracts as free and incorporated in liposome were added at 200, 600 and $1000 \mathrm{mg} / \mathrm{L}$. Among samples containing green tea extracts, canola oils with green tea extract liposomes showed higher antioxidant efficiency than free green tea extracts. It can be explained green tea extracts liposomes are protect against unfavorable conditions (Lu et al., 2013). The highest and lowest peroxide value belonged control and $600 \mathrm{mg} / \mathrm{L}$ concentration green tea extract liposome ( $\mathrm{P}[?]$ 0.05). With increasing green tea extracts to $600 \mathrm{mg} / \mathrm{L}$, antioxidant efficiency also increased but further increasing of extract concentration to $1000 \mathrm{mg} / \mathrm{L}$, may cause to decreased antioxidant efficiency. Wanasundara and Shahidi applied green tea extract in 500 and $1000 \mathrm{mg} / \mathrm{L}$ on seal blubber oil and menhaden oil. They found green tea extract, at concentration of $1000 \mathrm{mg} / \mathrm{L}$ in both oil 
samples, had prooxidant effect and said this effect could be because existence chlorophyll (Wanasundara and Shahidi.,1997). Also, Endo et al. reported chlorophyll and their derivatives caused lipids oxidation progress (Endo et al., 1985). Chen et al. studied on the antioxidant effects on ethanolic extract of green, yellow and white, black, dark-green and oolong teas on the heated canola oil at $100 \mathrm{degC}$. The results indicated that green, white and yellow extracts showed higher antioxidant activity in compare to BHT to inhibit oxidation canola oil (Chen et al., 1996). Hassan et al. used of olive leaf ethanolic, methanolic and water extract as natural antioxidant on the canola oil. The lowest peroxide value related to ethanolic extracts followed by methanolic and water extracts (Hassan et al., 2013). Koketsu and Satoh compared antioxidant effects of green tea polyphenols at 40 and $60 \mathrm{mg} / \mathrm{L}$ and tocopherol in the $200 \mathrm{mg} / \mathrm{L}$ concentration on the soybean oil. Green tea polyphenols showed stronger antioxidant effects as compared tocopherol. They reported induction time for reaching a peroxide value $100 \mathrm{meq} / \mathrm{kg}$ was 27,24 and 16 for control and oil samples with 40 and 60 mg/L green tea polyphenols (Koketsu and Satoh., 1997).

Table 1

\section{Anisidine Value}

To determine oxidation progression, peroxide value alone is not enough. Because it shows only primary oxidation productions. p-Anisidine value is an indicator to measure lipid oxidation secondary products. This method determines the aldehydes amount principally 2-alkenals and 2, 4-alkadienals vegetable oils (Shahidi, 1997). The anisidine value of canola oils is shown in Table 2 . The results showed green tea extract has acted as an effective natural antioxidant. In addition to, it was found that green tea extract liposomes had the better function than free extracts. The most important reason of this phenomenon is the controlled release of green tea extracts from liposome and protection of extract's polyphenols against unfavorable conditions that cause to increase antioxidant properties (Lu et al., 2011). The findings displayed, the extract concentration and the increasing storage time in oven had the significant effect on anisidine test of canola oil (P[?]0.05). The best antioxidant function was observed at $600 \mathrm{mg} / \mathrm{L}$ of green tea extract liposome. While the control samples had the highest anisidine value that determined a higher rate of secondary products formation of lipids oxidation.

Table 2

\section{TOTOX Value}

TOTOX values of canola oil samples are shown in Table 3. The obtained results determined green tea extracts whether free or encapsulated in liposome was acted in the form of an effective antioxidant and was while green tea extract liposomes were stronger in the retarding oxidation rate than free extracts. The lowest TOTOX value related to green tea extract liposome at $600 \mathrm{mg} / \mathrm{L}$. Shahidi and Wanasundara reported TOTOX values, in the treated canola oils with canola extract, were lower than control (Shahidi and Wanasundara., 1997).

\section{Table 3.}

\section{Thiobarbituric Acid Reactive Substances (TBARS)}

TBA test is an index of secondary oxidation products which can use for monitoring vegetable oils oxidation (Shahidi \& Wanasundara., 1997). In this research, the addition green tea extracts as free and encapsulated in liposome had a significantly affect (P[?]0.05) in reducing TBARS formation as compared control canola oils that have shown in Table 4. Among green tea extracts, liposomes containing extracts had better efficiency to decrease canola oil oxidation. The lowest TBA value was observed at $600 \mathrm{mg} / \mathrm{L}$ concentration of liposomal extract of green tea. Zokti et al. reported, encapsulated green tea extracts had the higher antioxidant activity than free green tea extract in mango drink (Zokti et al., 2016). Free green tea extract at concentration of $600 \mathrm{mg} / \mathrm{L}$ and liposomal extract at 200, 600 and $1000 \mathrm{mg} / \mathrm{L}$ showed higher efficiency in compare to BHT. The obtained results are in agreement with other reports (Semwal \& Arya., 2001; Hassan et al., 2013). They found TBA values, respectively, on the sunflower and canola oils, increased during storage time. 


\section{Table 4}

\section{Conclusion}

The obtained extracts of green tea were very effective to prevent of the primary and secondary oxidation products in the studied canola oil. Green tea extract both free and incorporated in liposome showed a good antioxidant activity. The $600 \mathrm{mg} / \mathrm{L}$ concentration of green tea extract had stronger antioxidant properties than BHT and other green tea concentrations that its reason can be extract polyphenols. In addition to, the results determined green tea extract liposomes possessed powerful antioxidant activity that showed liposome structure caused to improve the stability of tea polyphenol. The increasing storage time caused to upward trend of canola oil oxidation. While the increasing green tea extract concentration from 200 to $600 \mathrm{mg} / \mathrm{L}$ had a significant impact in preventing of oxidation process $(\mathrm{P}[?] 0.05)$ but green tea extract in concentration of $1000 \mathrm{mg} / \mathrm{L}$ did not show any strong antioxidant activity and causing delay in canola oil oxidation. This study determined natural antioxidants such as green tea extract can be a good alternative instead of synthetic antioxidants.

\section{Conflict of Interest}

The authors declare that there are no conflicts of interest.

\section{Acknowledgement}

Authors are grateful to the Shahid Beheshti University of Medical Sciences for finical support.

\section{References}

Abbas, M., Nouruddeen, Z.B., Muhamad, II., Latip, R.A., Othman, N.H. (2013). Effect of microwave heating on the quality characteristics of canola oil in presence of palm olein. Acta Sci. Pol., Technol . Aliment. 12(3): 241-251.

Ahmad, M., Baba, W.N., Shah, U., Gani, A., Gani, A., \& Masoodi, F.A. (2014). Nutraceutical properties of the green tea polyphenols. Journal of Food Processing \& Technology . 5 : 390. DOI:10.4172/21577110.1000390 .

A.O.A.C. (1984). Official Methods of Analysis Association of Official Analytical Chemists.12th ed. William Hormitz.

AOCS, (1996). Official methods and recommended practices of the american oil chemists' society (4 ${ }^{\text {th }}$ ed): Champaign: AOCS Press.

A.O.C.S (1998) : Official and Tentative Methods of the American Oil Chemists Society (5th ed). American Oil Chemists Society, 35 East Waker Drive, Chicago, Illinois USA.

Besbes, S., Blecker, C., Deroanne., C., Lognay, G., Drira, N.E. and Attia, H. (2004). Quality characteristics and oxidative stability of date seed oil during storage. Food Science Technology International .10 : 333-338. doi.org/10.1177/1082013204047777.

Bitar, A., Ghaddar, T., Malek, A., Haddad, T., Toufeili, I.(2008). Sensory Thresholds of Selected Phenolic Constituents from Thyme and their Antioxidant Potential in Sunflower Oil.Journal of the American Oil Chemists' Society. 85, 641-646. doi.org/10.1007/s11746-008-1244-8.

Chander, R., Khanna., A. K., Kanwal., R. and Rastogi, A. K., (2005). Antioxidant and Lipid Lowering Activities of Indian Black Tea.Indian J. Clinical Biochem . 20 :153-159. doi.org/10.1007/BF02893063.

Chen, ZY., Chan, PT., Ma, HM., Fung, KP., Wang, J. (1996). Antioxidative effect of ethanol tea extracts on oxidation of canola oil.Journal of American Oil Chemists Society. 73 (3) doi.org/10.1007/BF02523434.

Desai, K.G.H., Park, H.J. (2005). Recent developments in microencapsulation of food ingredients. Drying Technol .23 :1361-1394. doi.org/10.1081/DRT-200063478. 
Endo, Y., Usuki, R. and Kaneda, T. (1985). Antioxidant effects on chlorophylls and pheophytin on the autoxidation of oils in the dark. Journal of the American Oil Chemists' Society.62:1387-1390. doi.org/10.1007/BF02545962.

Frankel, EN. (1993). In search of better method to evaluate natural antioxidants and oxidative stability in food lipids. Trends in Food Science and Technology . 4 . doi.org/10.1016/0924-2244(93)90155-4.

Gramza, A., Khokhar, S., Yoko, S., Gliszczynska-Swigloc, A., Hesa, M., Korczaka, J.(2006). Antioxidant activity of tea extracts in lipids and correlation with polyphenol content. European Journal of Lipid Sci. Technol . 108 :351-362. doi.org/10.1002/ejlt.200500330.

Hassan, M., ELsayed, MM., Zaki, AM., Zaki, A.M., Hatour, F.S., Gazwy, S.S. (2013). Effect of olive leaf extracts (OLEs) as antioxidants on the biochemical changes in canola oil during heating. J. Agric. Chem. Biotechn., Mansoura Univ . 4 (10): 347-357. DOI: 10.21608/jacb.2013.53230.

Jahanfar, SH., Ghavami, M., Khosravi-Darani, K., Jahadi, M. (2020). Liposomal Green Tea Extract: Optimization and Physicochemical Characterization. Journal Appl Biotechnol Report, revised.

Jeong, SM., SY, Kim., DR, Kim., SC, Jo., KC, Nam., DU, Ahn., and SC, Lee. (2004). Effect of heat treatment on the antioxidant activity of extracts from citrus peals. J. Agric. Food Chem . 52 : 3389-3393. doi:10.1021/jf049899k.

Koketsu, M., Satoh, YU. (1997). Antioxidative Activity of Green Polyphenols in Edible Oils. Journal of Food Lipids .4 :1-9. doi.org/10.1111/j.1745-4522.1997.tb00076.x.

Langley-Evans, S.C. (2000). Antioxidant potential of green and black tea determined using the ferric reducing power (FRAP) assay.International Journal of Food Sciences and Nutrition .51 :181-188. doi.org/10.1080/09637480050029683.

Laubli, M.W., Bruttel, P.A. (1986). Determination of the oxidative stability of fats and oils: comparison between the active oxygen method (AOCS Cd 12-57) and the Rancimat method.Journal of the American Oil Chemists' Society.63(6) 792-795. doi.org/10.1007/BF02541966.

Livney, Y.D. (2015). Nanostructured delivery systems in food: Latest developments and potential future directions. Current Opinion in Food Science . 3 :125-135. doi.org/10.1016/j.cofs.2015.06.010.

Lu, Q., Li, D.C., Jian, J.G. (2013). Preparation of a Tea Polyphenol Nanoliposome System and Its Physicochemical Properties. J. Agric. Food Chem . 59 :13004.13011. doi.org/10.1021/jf203194w.

Mandel, S., Weinreb Amit, T., and Youdim, M.B.H. (2004). Cell signaling pathways in the neuroprotective actions of green tea polyphenol epigallocatechin-3-gallate: Implications for neurodegenerative diseases. Journal of Neurochemistry . 88 : 1555-1569. doi.org/10.1046/j.1471-4159.2003.02291.x.

Mozafari, M., Khosravi-Darani, K.(2007). An overview of liposome-derived nanocarrier technologies. In; Nanomaterials and Nanosystems for Biomedical Applications, Springer, Dordrecht, pp. 113-123. DOI https://doi.org/10.1007/978-1-4020-6289-6_7.

Noudoost, B., Noori, N., Amo Abedini, G., Gandomi, H., Akhondzadeh Basti, A., Jebeli Javan, A., and Ghadami F. (2015). Encapsulation of green tea extract in nanoliposomes and evaluation of its antibacterial, antioxidant and prebiotic properties. Journal of Medicinal Plants. 3(55 ):66-78.

Nwuha, W., Nakajima, M., Tong, J., Ichikawa., S. (1999). Solubility study of green tea extracts in pure solvents and edible oils. J Food Eng . 40 :161-165. doi.org/10.1016/S0260-8774(99)00050-3.

Ou, B., Hampsch-Woodill, M., and Prior, R.L. (2001). Development and Validation of an Improved Oxygen Radical Absorbance Capacity Assay Using Fluorescein as the Fluorescence Probe. J. Agric. Food Chem .49 : 4619-4626. doi.org/10.1021/jf010586o. 
Rains, T.M., Agarwal, S.,and Maki, K.C. (2011). Antiobesity effects of green tea catechins: A mechanistic review. Journal of Nutritional Biochemistry . 22 :1-7. doi.org/10.1016/j.jnutbio.2010.06.006.

Rasti, B., Jinap, S., Mozafari, M., and Yazid, A. (2012). Comparative study of the oxidative and physical stability of liposomal and nanoliposomal polyunsaturated fatty acids prepared with conventional and Mozafari methods. Food Chemistry . 135(4 ):2761-277. doi.org/10.1016/j.foodchem.2012.07.016.

Semwal, A.D., Murthy, N.M.C., Sharma, G.K. and Arya, S.S. (1996). Studies on storage stability of commercially marketed refined sunflower oil in plastic film packs. J Food SciTechnol . 33(4 ): 352-354.

Setyopratomo, P. (2014). Extraction of phenolic compounds from green tea using ethanol. ARPN Journal of Engineering and Applied Sciences,9.

Shahidi, F. (1990). In Canola and Rapeseed, Production, Chemistry, Nutrition and Processing Technology. pp 81-98, Van Nostrand Reinhold, New York.

Shahidi, F. (1997). Natural antioxidants: An over view. In: F.Shahidi (Ed.), Natural antioxidant, Chemistry, Health Effects and Applications, (pp. 1-10). Champaign, IL, USA: AOCS press.

Shahidi, F., Wanasundara, U. (1997). Effect of natural antioxidants on the stability of canola oil. Developments in Food Science . doi.org/10.1016/S0167-4501(06)80173-1.

Shpigelman, A., Cohen, Y., and Livney, Y.D. (2012). Thermally-induced blactoglobulin-EGCG nanovehicles: Loading, stability, sensory and digestive release study. Food Hydrocolloids . 29 : 57-67. doi.org/10.1016/j.foodhyd.2012.01.016.

Tang, D.W., Yu, S.H., Ho, Y.C., Huang, B.Q., Tsai, G.J., Hsieh, H.Y., Mi, F.L. (2013). Characterization of tea catechins-loaded nanoparticles prepared from chitosan and an edible polypeptide. Food Hydrocolloids . 30 : 33-41. doi.org/10.1016/j.foodhyd.2012.04.014.

Tokarska, B., Hawrysh, Z.J., Clandinin, MT. (1986). Study of the Effect of Antioxidants on Storage Stability of Canola Oil Using Gas Liquid Chromatography. Canadian Institute of Food Science and Technology Journal.19(3), 130-133. doi.org/10.1016/S0315-5463(86)71466-1.

Vuong, Q.V., Golding, J.B., Stathopoulos, C.E., Nguyen, M.H and Roach, P.D.J. (2011). Optimizing conditions for the extraction of catechins from green tea using hot water. Journal of Separation Science . 34(21 ), 3099-3106. doi: 10.1002/jssc.201000863.

Wanasundara, U.N., Shahidi, F. (1997). Antioxidant and pro-oxidant activity of green tea extracts in marine oil. Food Chemistry .63 (3), 335-342. doi.org/10.1016/S0308-8146(98)00025-9.

Yanishlieva-Maslarowa, N.V., Heinonen, I.M. (2001). Sources of natural antioxidants: Vegetables, fruits, herbs, spices and teas. In: Antioxidants in Food - Practical Applications. Eds. J. Pokorny, N. Yanishlieva, M. Gordon, CRC Press, Woodhead Publishing, Cambridge (UK), pp. 210-249.

Yin, JIE., Becker, EM., Andersen, ML., Skibsted, LH. (2012). Green tea extract as food antioxidant. Synergism and antagonism with a-tocopherol in vegetable oils and their colloidal systems. Food chemistry . 135 : 2195-2202. doi.org/10.1016/j.foodchem.2012.07.025.

Zhang, L., Zheng, Y., Chow, M. S., \& Zuo, Z. (2004). Investigation of intestinal absorption and disposition of green tea catechins by Caco-2 monolayer model. International Journal of Pharmaceutics .287 :1-12. doi.org/10.1016/j.ijpharm.2004.08.020.

Zhou, K., Ly, Yu. (2004). Effects of extraction solvent on wheat bran antioxidant activity estimation. LWT-Food Science and Technology . 37 :717-721. doi.org/10.1016/j.lwt.2004.02.008.

Zokti, J., Badlishah Sham Baharin, A., Abdulkarim, SM., Abas, F. (2016). Microencapsulation of Green tea Extracts and its Effects on the Physico-Chemical and Functional Properties of Mango Drinks.International Journal of Basic 83 Applied Sciences.16 (2). 


\section{Figure Legend:}

Figure. 1. Green tea extracts influence on canola oil stability, expressed as induction period value (Ip[h]), under Rancimat test conditions. a, b, c, d, e, f, g, h. mean values with different letters differ statistically between lines.

\section{Hosted file}

Table 1.docx available at https://authorea.com/users/324665/articles/452774-antioxidantactivity-of-green-tea-extract-on-canola-oil-oxidation-stability-comparison-of-free-andliposomal-extract

\section{Hosted file}

Figure.docx available at https://authorea.com/users/324665/articles/452774-antioxidantactivity-of-green-tea-extract-on-canola-oil-oxidation-stability-comparison-of-free-andliposomal-extract 